\title{
The influence of the $\mathrm{CO}_{2}$ pneumoperitoneum on a rat model of intestinal anastomosis healing
}

\author{
Stefaan H. A. J. Tytgat • Ger T. Rijkers • \\ David C. van der Zee
}

Received: 20 July 2011/Accepted: 21 November 2011/Published online: 17 December 2011

(C) The Author(s) 2011. This article is published with open access at Springerlink.com

\begin{abstract}
Background The $\mathrm{CO}_{2}$ pneumoperitoneum, which is used for laparoscopic surgery, causes local and systemic effects in patients. Concern arises about what the pressurized anoxic environment of the $\mathrm{CO}_{2}$ pneumoperitoneum has on intestinal healing. Earlier experimental work showed a negative correlation between intestinal healing and the applied intra-abdominal pressure. To further elucidate this, we developed a rat model, in which enterotomy healing can be compared after open or laparoscopic surgery. Possible mechanisms of injury, such as impaired neoangiogenesis or injury through hypoxia-induced pathways were studied.

Methods A new experimental mechanically ventilated rat model was developed. An enterotomy was made and closed via laparotomy (group I) or laparoscopy under $\mathrm{CO}_{2}$ pressures of $5 \mathrm{mmHg}$ (group II) or $10 \mathrm{mmHg}$ (group III). Intestinal healing was tested in vivo after 1 week by bursting-pressure analysis. The effect of the operative procedure on neoangiogenesis was tested by counting factor VIII positive vessels in biopsies of the perianastomotic granulation tissue after 1 week. Intestinal anoxia was tested by quantifying HIF- $1 \alpha$ protein levels in intestinal biopsies, taken before the enterotomy closure.

Results The bursting pressures were significantly lower

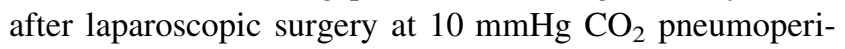
toneum (group III) compared with rats that had undergone open surgery (group I) or laparoscopic surgery at $5 \mathrm{mmHg}$
\end{abstract}

S. H. A. J. Tytgat $(\bowtie) \cdot$ D. C. van der Zee

Department of Pediatric Surgery, Wilhelmina Children's

Hospital, University Medical Center Utrecht, KE.04.140.5,

P.O. Box 85090, 3508, AB, Utrecht, The Netherlands

e-mail: s.tytgat@umcutrecht.nl

G. T. Rijkers

Department of Surgery, University Medical Center Utrecht, Utrecht, The Netherlands
$\mathrm{CO}_{2}$ pneumoperitoneum (group II). There was no significant quantitative difference between the three groups in the neoangiogenesis nor was there a difference in the amount of HIF- $1 \alpha$ measured in the intestinal biopsies.

Conclusions We developed a surgical model that is well fitted to study the effects of pneumoperitoneum on intestinal healing. With this model, we found further evidence of $\mathrm{CO}_{2}$ pressure-dependant hampered intestinal healing. These differences could not be explained by difference in neoangiogenesis nor local upregulation of hypoxic factors.

Keywords Anastomosis healing $\cdot$ Rat model $\cdot \mathrm{CO}_{2}$. Pneumoperitoneum $\cdot$ Neoangiogenesis $\cdot$ HIF-1 alpha

With the growing number of minimally invasive procedures, concern arises about the possibly detrimental effect of $\mathrm{CO}_{2}$ pneumoperitoneum on intestinal healing. We hypothesized that the pressurized anoxic carbon dioxide environment influences early intestinal healing of enterotomies. Earlier experimental work showed that increased abdominal pressure causes impaired anastomotic healing [1-4]. To further examine this phenomenon, we developed a rat model in which enterotomy healing can be compared after open or laparoscopic surgery. Possible mechanisms of injury, such as impaired neoangiogenesis or injury through hypoxia-induced pathways were studied.

\section{Materials and methods}

Animals

Male Wistar Albino rats, weighing 300 to $350 \mathrm{~g}$, were obtained from Harlan, Zeist, The Netherlands. After arrival 
at our animal facility, they were housed under standard laboratory conditions and acclimatized for 1 week to a $12 \mathrm{~h}$ light/dark cycle and room temperature between 22 and $24^{\circ} \mathrm{C}$. They received normal rodent chow and water ad libitum. After the surgical procedure, body weight was measured daily as a function of well being and of bowel function.

The rats were divided into three groups: group I in which the operation was performed as an open procedure; group II in which the operation was performed via laparoscopy with maximal insufflation pressure of $5 \mathrm{mmHg}$; and group III, laparoscopic group with insufflation pressure of maximum $10 \mathrm{mmHg}$. All experiments were performed in accordance of the Animal Welfare Committee of the University Medical Center Utrecht.

\section{Surgical procedure}

Perioperative analgesia consisted of intramuscular Temgesic $^{\circledR}$ administration for $24 \mathrm{~h}$. After induction of anesthesia with isoflurane, the trachea was intubated with a 14-G Venflon catheter. A Bear $\mathrm{Cub}^{\circledR}$ infant respiratory ventilator was used for maintaining isoflurane inhalation anesthesia at a rate of $40 \times / \mathrm{min}$ and at pressures of $18 \mathrm{mmHg}$ over $8 \mathrm{mmHg}$ PEEP. The rats were shaved, and the abdomen was disinfected. Animals were operated on a heated operating table in a $3 / 4$ supine-right side position. For the laparoscopic procedure, $3 \mathrm{~mm}$ instruments were used (Karl Storz, Tuttlingen, Germany). The instruments were disinfected with alcohol before surgery. Three $3.5 \mathrm{~mm}$ trocars were placed in the abdominal midline. The trocars have a $5 \mathrm{~cm}$ shaft, over which we placed a little silicone tube of $5 \mathrm{~mm}$. The shaft was inserted through the abdominal wall up to the silicone ring. Both the ring and shaft were secured by a pursestring suture to prevent any air leak. $\mathrm{A} \mathrm{CO}_{2}$ pneumoperitoneum of 5 or $10 \mathrm{mmHg}$ with a flow of $0.5 \mathrm{~L} / \mathrm{min}$ was applied by an Endoflator (Karl Storz, Tuttlingen, Germany). Standard $\mathrm{CO}_{2}$ gas was used at room temperature. One trocar was used for a $3 \mathrm{~mm} 30^{\circ}$ scope. The camera was fixed to the operation table. Instruments were placed through two trocars, placed cranially and caudally of the camera in the midline. In open surgery, the abdomen was opened via a midline incision. The operative procedure was similar in all groups. The laparotomy time of the open procedure was matched to the time needed for laparoscopic procedure of the previous rat. This way we achieved comparable total operative time in all groups.

The procedure was started with inspection of the abdomen and identification of the cecum. A segment of the terminal ileum, at approximately $5 \mathrm{~cm}$ from the ileocecal junction, was identified and brought to the left side of the abdomen. After gently evacuating intestinal content with non-traumatic forceps, an incision of half of the circumference at the antimesenteric side was made. A biopsy was taken from the distal side of the enterotomy for quantification of hypoxia induced factors. The biopsies were taken at $10 \pm 2$ minutes in group II and at $11 \pm 3$ minutes in group III after installation of the pneumoperitoneum (NS). In open surgery, the interval between intubation and the biopsy was matched to the interval that was recorded in the laparoscopic procedure of the previous rat. Then, the enterotomy was closed. In all groups, five interrupted absorbable 5.0 (Vicryl $^{\mathrm{TM}}$, Ethicon) sutures that contained the full intestinal wall were placed to achieve a single layer enterotomy closure. Laparoscopic sutures were performed fully intracorporeally. In the open group, the sutures were placed in the exteriorized intestinal loop. The first laparoscopic suture was exteriorized through the opposite abdominal wall to keep the segment in view of the fixed camera during the further closure of the enterotomy. The trocars were removed under laparoscopic vision. The abdominal wall was closed in two layers with absorbable 4.0 sutures (Vicryl ${ }^{\mathrm{TM}}$, Ethicon). The rats were extubated after regaining consciousness.

\section{Bursting pressure}

The strength of the enterotomy was tested in vivo after 1 week by measuring the bursting pressure [1]. The abdomen was accessed via a midline laparotomy under isoflurane inhalation anesthesia. The segment with the enterotomy was ligated on one side, and the other side was connected via a cannula to an infusion pump with saline solution. A pressure transducer and recorder were connected via a side-arm of the canula. The saline solution filled the segment with a constant rate of $60 \mathrm{ml} /$ hour. A rapid decline of pressure was recorded when burst occurred. The maximum pressure achieved just before burst was recorded as the bursting pressure [5].

\section{Immunohistochemistry}

A biopsy of the anastomotic line was excised after the bursting pressure experiment. A quantification of the neoangiogenesis in the granulation surrounding the anastomosis was performed by counting factor VIII positive vessels. The procedure was described previously [5]. In short, the segment was first fixed with formaldehyde $4 \%$ and embedded in paraffin. The granulation was identified after section of the biopsies and eosin-staining with hematoxylin. The selected tissue was deparaffinized and incubated for $10 \mathrm{~min}$ in hydrogen peroxide. After pretreatment with pepsin, the slides were preincubated with normal goat serum for $15 \mathrm{~min}$. Then, the tissue was incubated for $1 \mathrm{~h}$ with a polyclonal antibody against factor VIII (DAKO, Carpinteria, CA). Followed by incubation with a 
biotinylated goat anti-polyvalent secondary antibody with large-volume streptavidin peroxidase (Lab Vision, Fremont, CA), which was followed by $3,3^{\prime}$-diaminobenzide tetrahydrochloride as chromogen. Sections were counterstained with hematoxylin and dehydrated.

Granulation tissue surrounding the anastomotic line was analyzed microscopically ( $\times 40$ objective, $\times 10$ ocular). Factor VIII-positive vessels were counted in four different fields. Angiogenesis was expressed as the average number of vessels per field.

HIF- $1 \alpha$ determination by bead-based immunoassay

One hundred $\mu$ PBS containing $10 \mu 1 / \mathrm{ml}$ of a cocktail of protease inhibitors (Sigma, Zwijndrecht, The Netherlands) was added to frozen biopsies, which were subsequently grinded with a mortar and pastel cooled in liquid nitrogen. The homogenates were stored at $-80^{\circ} \mathrm{C}$ until analysis of HIF- $1 \alpha$. Homogenates were thawed, centrifuged for $5 \mathrm{~min}$ $(10,000 \times g)$ and the supernatant was used for determination of HIF- $1 \alpha$. To that end, $50 \mu \mathrm{l}$ of the undiluted biopsy supernatant or standard (recombinant HIF- $1 \alpha$ (Bioconnect, Huissen, The Netherlands) was incubated with anti-HIF-1 $\alpha$ antibody-coated beads (Bioconnect, Huissen, the Netherlands and Luminexcorp, Austin, TX, USA) in a 96-well $1.2 \mu \mathrm{m}$ filter plate. After $60 \mathrm{~min}$ of incubation, a biotinylated secondary rabbit anti-human HIF- $1 \alpha$ antibody (Abcam, Cambridge, UK) was added to each well and incubated for another $60 \mathrm{~min}$. After subsequent incubation for $30 \mathrm{~min}$ with streptavidin-PE (Bio-Rad, Veenendaal, the Netherlands) the fluorescence intensity of the beads was measured using the Bio-Plex system in combination with the Bio-Plex Manager software version 5.0 (Bio-Rad). HIF- $1 \alpha$ concentrations were calculated from an 8-point standard curve, ranging from 20,000 to 9.14 picogram $/ \mu$ l. Total protein content in the supernatants was quantified using a BCA ${ }^{\circledR}$ protein assay kit (Pierce, Rockford, IL). HIF- $1 \alpha$ concentrations are expressed as $\mathrm{pg} / \mu \mathrm{g}$ biopsy protein.

\section{Statistical analysis}

Mann-WhitneyAnalysis of the data was performed with SPSS 15.0 for Windows software on a PC. Analysis was performed by using the $U$ test. Differences between groups were considered to be statistically significant when a $P$ value $<0.05$ was found.

\section{Results}

The rats were randomly assigned to one of three groups: group I consisted of rats undergoing open surgery $(n=23)$; group II rats were operated by laparoscopy under
$5 \mathrm{mmHg} \mathrm{CO}_{2}$ pressure $(n=23)$; and group III rats underwent the laparoscopic procedure under $10 \mathrm{mmHg}$ $\mathrm{CO}_{2}$ pressure $(n=23)$. In group I, two rats were excluded: one because of respiratory failure due to intubation injury, and one for technical failure at the bursting pressure measurement. In group II, two rats were excluded due to respiratory failure due to intubation injury. In group III, all rats were included. All rats were weighed before surgery and during the week after surgery. Initial weight and weight loss after 1 week were comparable in all groups (Table 1). Total operation time from intubation to extubation was similar in all groups, because we matched the operation time of rats in the open surgery group to the time needed for a procedure from the previous laparoscopic surgery group. Also the total pneumoperitoneum time was similar in both laparoscopic groups (groups II and III; Table 1).

The bursting pressures at 1 week were significantly lower in group III (10 $\mathrm{mmHg} \mathrm{CO} \mathrm{CO}_{2}$ pneumoperitoneum) compared with rats that had undergone open surgery (group I) or laparoscopic surgery at $5 \mathrm{mmHg} \mathrm{CO}$ (group II) pneumoperitoneum (Table 1; Fig. 1). There was no difference in bursting pressure if we compared group I (open) and group II (5 $\mathrm{mmHg} \mathrm{CO}$ ).

Neoangiogenesis was quantified by measuring factor VIII-positive vessels in the granulation tissue that surrounds the anastomosis. There was no significant difference in the quantified neoangiogenesis between the three groups (Table 1).

As a marker of perioperative ischemia, we quantified HIF- $1 \alpha$ concentrations in the intestinal biopsies taken during surgery. The amount of HIF-1 $\alpha$ was similar in all groups (Table 1).

\section{Discussion}

We set up this study to determine the effect of the intraabdominal $\mathrm{CO}_{2}$ pneumoperitoneum pressure on intestinal healing. Although clinical leakage rates of laparoscopic bowel resections are comparable to open surgery leakage rates, we believe that further research of the physiological effects of the pneumoperitoneum are justified. Our hypothesis is that a better understanding of these effects might lead to even safer minimally invasive surgery in the future.

Earlier experimental work in rats had shown a correlation of applied intra-abdominal pressures and impaired anastomotic strength at 5 to 7 days. Kologlu found this effect after applying intra-abdominal pressures of over $6 \mathrm{mmHg}$ for 4 days [2]. Polat tested the effect of pressures over $14 \mathrm{mmHg}$ applied for $1 \mathrm{~h} \mathrm{[1]}$. Ozgun found impaired anastomotic healing if the applied pressure was more than 
Table 1 Characteristics of the three experimental groups

\begin{tabular}{|c|c|c|c|c|}
\hline$N$ & $\begin{array}{l}\text { Group I, open } \\
\text { surgery } \\
21\end{array}$ & $\begin{array}{l}\text { Group II } \\
(5 \mathrm{mmHg}) \\
21\end{array}$ & $\begin{array}{l}\text { Group III } \\
(10 \mathrm{mmHg}) \\
23\end{array}$ & $P$ \\
\hline Weight at surgery (g) (range) & $362(329-409)$ & $373(346-416)$ & $368(338-404)$ & 0.378 \\
\hline Weight 1 week after surgery (g) (range) & $353(326-415)$ & $363(334-405)$ & $357(317-393)$ & 0.451 \\
\hline Mean operation time minutes mean (range) & $58(43-75)$ & $56(43-71)$ & $55(43-72)$ & 0.115 \\
\hline Duration of pneumoperitoneum, min (range) & _ & $43(29-57)$ & $43(29-64)$ & 0.716 \\
\hline Bursting pressure (mmHg, mean) (SEM) & $292(6.9)$ & $279(7.6)$ & $253(7.4)$ & $\begin{array}{l}0.005 \text { between group I } \\
\text { and III } 0.0175 \\
\text { between II and III }\end{array}$ \\
\hline $\begin{array}{l}\text { Angiogenesis, F VIII-positive } \\
\text { vessels/view, mean (SD) }\end{array}$ & $18.6(9.3)$ & $19.8(10)$ & $16.4(10.1)$ & NS \\
\hline HIF- $1 \alpha$ concentration in biopsies $(\mathrm{pg} / \mu \mathrm{g})$ protein, mean $(\mathrm{SD})$ & $3.01(1.4)$ & $2.64(1.7)$ & $2.76(1.5)$ & NS \\
\hline
\end{tabular}

Group I rats had undergone open surgery. Groups II and III had undergone laparoscopic surgery at 5 and $10 \mathrm{mmHg} \mathrm{CO}_{2}$ pneumoperitoneum, respectively

Mean weight before surgery and at 1 week is stated in grams

Mean operative time from intubation to extubation and total pneumoperitoneum time are stated in minutes

Mean bursting pressure of the operated intestinal segment after 1 week is expressed in $\mathrm{mmHg}$

Angiogenesis in the granulation tissue was measured by counting Factor VIII-positive vessels

Values are expressed as mean number of vessels per field and SD

HIF- $1 \alpha$ concentration of perioperative intestinal biopsies are expressed as $\mathrm{pg} / \mu \mathrm{g}$ biopsy protein

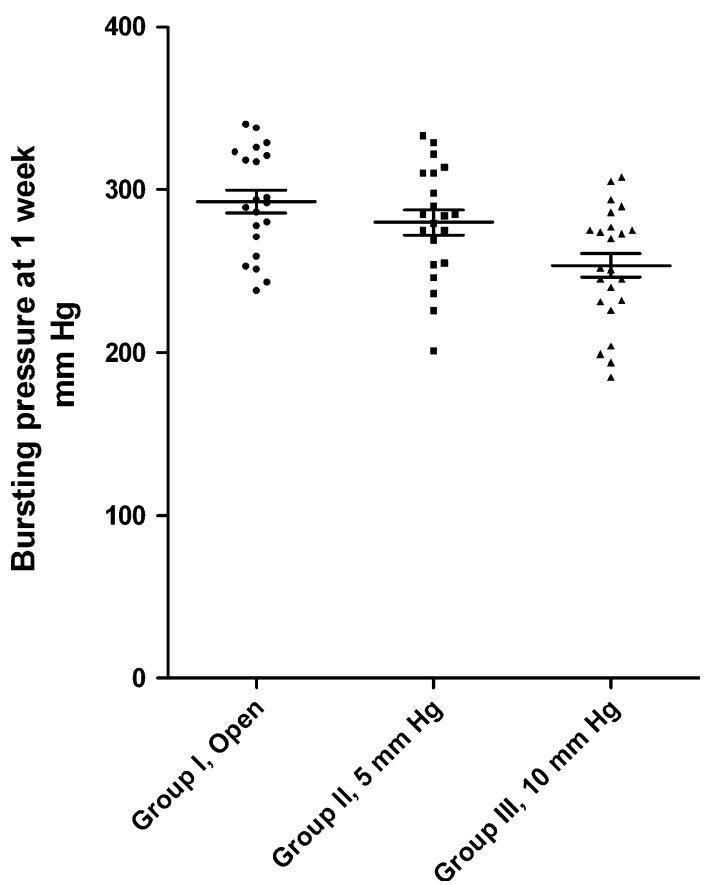

Fig. 1 In vivo bursting pressures of intestinal loops. One week after enterotomy closure, via open surgery (group I), or laparoscopic surgery at $5 \mathrm{mmHg} \mathrm{CO}$ pneumoperitoneum (group II), or $10 \mathrm{mmHg}$ $\mathrm{CO}_{2}$ pneumoperitoneum (group III). Bursting pressures are expressed as means and SEM. $P=0.005$ between group I and III; $P=0.0175$ between II and III

$12 \mathrm{mmHg}$ for $3 \mathrm{~h} \mathrm{[3].} \mathrm{No} \mathrm{influence} \mathrm{on} \mathrm{anastomotic} \mathrm{healing}$ was found if low pressures of 3 or $6 \mathrm{mmHg}$ were applied for two sequential periods of $15 \mathrm{~min}$ [4]. Although these studies support the hypothesis that increased abdominal pressure might impair anastomotic healing, some caution has to be taken interpreting these results. Some of the applied pressures are substantially higher than pressures that we would normally recommend for laparoscopy in children and to a lesser extent in adults. Moreover, all animals in these series underwent open surgery via a laparotomy after a period of abdominal insufflation. Thus, actual surgery on the intestines was not performed during the pneumoperitoneum under the influence of the $\mathrm{CO}_{2}$ environment. Because the rats were not intubated, they were not mechanically ventilated with sufficient endexpiratory pressures, to prevent pulmonary failure, caused by the pneumoperitoneum. Studies have shown that with intubation, this ventilation regime can maintain arterial blood pressure and arterial oxygenation for a prolonged time in rats [6, 7] and in mice [8]. Therefore, we designed our model to test the intestinal healing in rats that that were mechanically ventilated and that underwent an open or a true laparoscopic procedure. The results confirm the earlier conclusion that there is a pressure-dependant effect on laparoscopic enterotomy healing.

As a measure of this healing, we chose to test the enterotomy strength at 1 week as published earlier [1]. We found a pressure dependant negative effect of the $\mathrm{CO}_{2}$ pneumoperitoneum on the enterotomy healing. If a pressure of only $5 \mathrm{mmHg} \mathrm{CO}_{2}$ was applied, this negative effect was not seen. Recent experimental work showed that ischemia-induced injury has greatest impact on intestinal anastomotic healing during the first 2 days after surgery 
[9]. In our study, a similar effect was still seen after a prolonged interval of 7 days.

To clarify the mechanisms that cause this pressuredependant impaired healing, we hypothesized that the pressurized anoxic environment might impair the early stages of intestinal healing. One measure of the quality of intestinal anastomotic healing is neoangiogenesis in the granulation tissue, which surrounds the anastomosis. Reparative angiogenesis is considered an essential step in anastomotic healing [10]. Impairing angiogenesis with antiangiogenic medication impairs intestinal anastomotic healing [5]. To quantify neoangiogenesis, we counted factor VIII-positive vessels. We found no correlation between the impaired anastomotic bursting pressure and the vessel density at the anastomosis. Therefore, we concluded that the applied pneumoperitoneum does not cause its effect on intestinal healing through impairment of the neoangiogenesis.

High intraperitoneal $\mathrm{CO}_{2}$ pressures of $15 \mathrm{mmHg}$ can cause peritoneal hypoxia in a mouse model with controlled respiratory support [11]. Therefore, we investigated whether there was evidence of ischemia at the anastomotic site. For this purpose, we measured the amount of Hypoxia Inducible Factor- $1 \alpha$ (HIF- $1 \alpha)$ in biopsies that were taken during the surgical procedure. HIF- $1 \alpha$ is a protein that is produced constantly in intestinal tissue. Under well-oxygenated conditions, it decays rapidly, but under anoxic conditions, it is not degraded and it becomes the first step in an ischemia cascade [12]. We hypothesized that the acidotic anoxic carbon dioxide environment would cause higher levels of HIF- $1 \alpha$ in the laparoscopic biopsies that were taken after 10-11 minutes after installation of the pneumoperitoneum. HIF- $1 \alpha$ levels were not higher in the laparoscopic groups compared with open surgery. Therefore, we concluded that the applied pneumoperitoneum pressures do not cause their effect on intestinal healing through an anoxic pathway.

In this paper, we present our model to test intestinal healing in open and laparoscopic surgery in rats. We designed the model to test intestinal healing under experimental conditions, which better resemble true laparoscopic or open intestinal surgery. As concluded in earlier experimental work, we also found a $\mathrm{CO}_{2}$ pressure-dependant impaired healing of intestinal anastomosis compared with open surgery. The model is technically feasible and reproducible. It is well fitted to study the effects of pneumoperitoneum on intestinal healing. To elucidate this phenomenon, we sought to find mechanisms of injury. Neither impaired neoangiogenesis nor local upregulation of hypoxic factors seem to be the mechanisms of action. Therefore, we would like to continue researching via which mechanisms these effects take place.
Acknowledgments The authors thank Ben de Jong, research technician at the Department of Medical Microbiology \& Immunology, Sint Antonius Hospital, Nieuwegein, for his expert technical assistance with the HIF- $1 \alpha$ determination by bead-based immunoassay. Inge Wegner, medical student at the University of Utrecht, who helped with the surgical procedures. Harry Meijer, Medical Measurement Systems, Nijmegen, who supplied the pressure transducer and software for the bursting pressure tests. And Karl Storz Endoscopy \& GmbH, Tuttlingen Germany, for supplying the instruments for the laparoscopic procedures.

Disclosures Stefaan Tytgat, Ger Rijkers, and David van der Zee have no conflicts of interest or financial ties to disclose.

Open Access This article is distributed under the terms of the Creative Commons Attribution Noncommercial License which permits any noncommercial use, distribution, and reproduction in any medium, provided the original author(s) and source are credited.

\section{References}

1. Polat C, Arikan Y, Vatansev C, Akbulut G, Yilmaz S, Dilek FH, Gokce O (2002) The effects of increased intraabdominal pressure on colonic anastomoses. Surg Endosc 16:1314-1319

2. Kologlu M, Sayek I, Kologlu LB, Onat D (1999) Effect of persistently elevated intraabdominal pressure on healing of colonic anastomoses. Am J Surg 178:293-297

3. Ozgun H, Boylu S, Cevikel MH, Yenisey C, Erpek H, Culhaci N, Demirkiran AE (2004) Effects of pneumoperitoneum with or without colostomy on rat colonic anastomotic healing. ANZ J Surg 74:158-163

4. Rosch R, Stumpf M, Junge K, Drinjakovic D, Schachtrupp A, Afify M, Schumpelick V (2005) Influence of pneumoperitoneum on small bowel anastomoses: a histological analysis in the rat model. J Invest Surg 18:63-69

5. te Velde EA, Voest EE, van Gorp JM, Verheem A, Hagendoorn J, Gebbink MF, Borel Rinkes IH (2002) Adverse effects of the antiangiogenic agent angiostatin on the healing of experimental colonic anastomoses. Ann Surg Oncol 9:303-309

6. Fuentes JM, Hanly EJ, Bachman SL, Aurora AR, Marohn MR, Talamini MA (2004) Videoendoscopic endotracheal intubation in the rat: a comprehensive rodent model of laparoscopic surgery. J Surg Res 122:240-248

7. Hazebroek EJ, Haitsma JJ, Lachmann B, Bonjer HJ (2002) Mechanical ventilation with positive end-expiratory pressure preserves arterial oxygenation during prolonged pneumoperitoneum. Surg Endosc 16:685-689

8. Bourdel N, Matsuzaki S, Bazin JE, Pouly JL, Mage G, Canis M (2007) Peritoneal tissue-oxygen tension during a carbon dioxide pneumoperitoneum in a mouse laparoscopic model with controlled respiratory support. Hum Reprod 22:1149-1155

9. Posma LA, Bleichrodt RP, Lomme RM, de Man BM, van Goor H, Hendriks T (2009) Early anastomotic repair in the rat intestine is affected by transient preoperative mesenteric ischemia. J Gastrointest Surg 13:1099-1106

10. Seifert WF, Verhofstad AA, Wobbes T, Lange W, Rijken PF, van der Kogel AJ, Hendriks T (1997) Quantitation of angiogenesis in healing anastomoses of the rat colon. Exp Mol Pathol 64:31-40

11. Matsuzaki S, Jardon K, Maleysson E, D'Arpiany F, Canis M, Bazin JE, Mage G (2010) Carbon dioxide pneumoperitoneum, intraperitoneal pressure, and peritoneal tissue hypoxia: a mouse study with controlled respiratory support. Surg Endosc 24:2871-2880 
12. Kannan KB, Colorado I, Reino D, Palange D, Lu Q, Qin X, Abungu B, Watkins A, Caputo FJ, Xu DZ, Semenza GL, Deitch EA, Feinman R (2011) Hypoxia-inducible factor plays a gut-injurious role in intestinal ischemia reperfusion injury. Am J Physiol Gastrointest Liver Physiol 300:G853G861 